\title{
Anatomical review of the mandibular lingula for inferior alveolar nerve block
}

\author{
D.-Y. Choi ${ }^{10}$, M.-S. Hur² \\ ${ }^{1}$ Department of Dental Hygiene, Catholic Kwandong University, Gangneung, South Korea \\ 2Department of Anatomy, Catholic Kwandong University College of Medicine, Gangneung, South Korea
}

[Received: 16 September 2020; Accepted: 25 October 2020; Early publication date: 3 November 2020]

\begin{abstract}
The purpose of this study was to perform a review of the literature related to the anatomy of the mandibular lingula and to provide information to improve the execution of effective anaesthesia of the inferior alveolar nerve in clinical practices of the mandible.

Prognathic mandibles have a lingula that is located more posterior and superior than non-prognathic mandibles. Most of the lingulae are located above the occlusal plane, but it is occasionally located at or below the occlusal plane. The lingula of the triangular shape was generally located slightly more superior and posterior than other shapes.

The mandibular lingula is an important anatomical landmark, and accurate information for exact lingula features is required during inferior alveolar nerve block anaesthesia. Proper evaluation of the lingula is key to effective anaesthesia and decreases the failure rate of the inferior alveolar nerve in clinical practices of the mandible. (Folia Morphol 2021; 80, 4: 786-791)
\end{abstract}

Key words: mandible, inferior alveolar nerve, nerve block, anatomy, morphology, location

\section{INTRODUCTION}

The mandibular lingula is often used clinically to approximate the location of the mandibular foramen. It is a salient structure with a tongue-shaped bony projection on the medial surface of the mandibular ramus near the mandibular foramen [23]. The mandibular foramen is the orifice of the mandibular canal, through which penetrates the inferior alveolar nerve, located inferiorly and posteriorly to the lingula. Thus, the mandibular lingula and mandibular foramen were considered as ideal anatomical landmarks for the surgeon, not only during inferior alveolar nerve block but also during surgical procedures such as orthognathic surgery [25].
The inferior alveolar nerve block is a widely used anaesthesia technique for the mandible. The most commonly used technique is called the direct approach, which includes inserting the needle into the pterygomandibular space by penetrating the buccinator muscle [12]. Once in this space, the aim is to put the local anaesthetic agent near the inferior alveolar nerve before it enters the mandibular foramen. The failure rate of the inferior alveolar nerve block has been reported to range from $10 \%$ to $39 \%$ [18]. This high failure rate can be attributed to various morphologies of the anatomical structures close to the inferior alveolar nerve, poor anaesthesia technique, psychological fear, or pathology [3]. 
The lingula is used for recognizing the site for injection of local anaesthetics or excision of the nerve for facial neuralgia [23]. Insufficient knowledge of the anatomy of the medial aspect of the mandibular ramus could be a reason for the failure of the inferior alveolar nerve block or complications such as nerve injury and haemorrhage $[10,11]$. It is possible to avoid these complications when the clinician is able to identify the lingula correctly.

Several methodologies have been used to study the anatomical features of mandibular fractures in many previous studies. They include examination of the dry mandible, panoramic radiograph, and three-dimensional image obtained from cone-beam computed tomography (CBCT). An investigation into the anatomical structures of the dry mandible to the naked eye has been used for a long time to clarify its morphology as a traditional method. Because a dry mandible can be measured directly, the measurement results are relatively accurate. Recently, examination of anatomical structures has become possible using radiography. Panoramic radiography provides useful information for locating the position of the mandibular lingula and the mandible [9]. However, measurements from panoramic radiographs have been disputed because of considerable distortions or methodological errors, although, it may be possible to reduce most of the distortions when using the standardised positioning of the head and the use of a bite block [14]. Three-dimensional images obtained from CBCT were reconstructed using a computer. This allows for a complex measurement of the distance to be taken more easily because it is possible to make a virtual line or plane and set up various anatomic landmarks in the three-dimensional images.

The differences in study design, origin, and age of the investigated specimens could account for the highly variable results. Thus, the purpose of this study was to perform a review of the literature related to the anatomy of the mandibular lingula and to provide information to improve the execution of effective anaesthesia of the inferior alveolar nerve in clinical practices of the mandible.

\section{MORPHOLOGY OF THE MANDIBULAR LINGULA}

Various shapes of the lingula have been reported by many authors. These different morphological shapes were classified into several types according to the previously reported studies. Lima et al. [15] classi- fied the mandibular lingulae into three types based on its shape: triangular, rectangular, or trapezoid. Fabian [6] reported five types of lingula based on shape and size: large nodular, small nodular, large triangular, small triangular, and small bony spicule type.

Most studies were performed using the classification proposed by Tuli et al. [23], according to whom, the shapes of the lingula were classified into four different types:

- triangular type: has a wide base and a narrow rounded or pointed apex;

- truncated type: has a quadrangular top;

- nodular type: is nodular with variable size;

- assimilated type: is completely incorporated into the ramus of the mandible.

The distribution and frequency of the four different morphological types of lingula varied among different authors, according to population and race. A study using Indian dry mandibles [23] showed that the triangular type $(68.5 \%)$ was the most common, followed by truncated (15.8\%), nodular (10.9\%), and assimilated (4.8\%). Other studies on the North Indian population $[4,19]$ were of the same order. Likewise, Lopes et al. [16] reported that the most common shape of the lingula was the triangular type (41.3\%) in a study of the Brazilian population, followed by truncated $(36.3 \%)$, assimilated $(11.9 \%)$, and nodular (10.5\%). Similarly, Desai et al. [5] reported triangular type $(51 \%)$ as the most common and assimilated $(12 \%)$ as the least common.

However, other studies reported that the nodular type was the most common. Sekerci and Sisman [20] studied the shape of the lingula using CBCT data of an adult Turkish population and reported that the nodular type was most common, present in $51.2 \%$ of cases, while the truncated, triangular, and assimilated types were present in $32 \%, 14.1 \%$, and $2.7 \%$ of cases, respectively. In other studies by Senel et al. [21] and Ahn et al. [1], the nodular type was the most prevalent, at $32.5 \%$ and $32.8 \%$, respectively. These studies showed that the triangular type was more common than truncated.

In contrast, the most prevalent shape of lingula was truncated type and the least prevalent shape was assimilated type, according to the results of studies on Thai populations. Jansisyanont et al. [8] studied dried Thai adult mandibles and reported that the truncated type $(46.2 \%)$ was the most common. This result was similar to that of Kositbowornchi et al. [14] who also reported that the most prevalent shape of the lingula was the truncated type (47.22\%). 
Table 1. Comparison between previous studies

\begin{tabular}{|c|c|c|c|c|c|c|c|c|c|c|c|c|c|c|}
\hline \multirow[t]{2}{*}{ Author (year) [Reference] } & \multirow[t]{2}{*}{ Population } & \multirow[t]{2}{*}{ Gender } & \multicolumn{3}{|c|}{ ML-AM } & \multicolumn{3}{|c|}{ ML-PM } & \multicolumn{3}{|c|}{ ML-IM } & \multicolumn{3}{|c|}{ ML-MN } \\
\hline & & & Right & Left & Total & Right & Left & Total & Right & Left & Total & Right & Left & Total \\
\hline Woo et al. (2002) [24] & Korean & Total & & & 18.6 & & & & & & & & & 19.8 \\
\hline \multirow[t]{2}{*}{ Jansisyanont et al. (2009) [8] } & Thai & Male & 20.9 & 20.6 & 20.6 & 18.2 & 18.4 & 18.0 & & & & 16.9 & 16.8 & 16.6 \\
\hline & & Female & 20.2 & 20.1 & & 17.4 & 17.3 & & & & & 16.0 & 15.9 & \\
\hline Samanta and Kharb (2012) [19] & Indian & Total & 20.0 & 20.2 & 20.0 & 14.9 & 15.2 & 15.0 & & & & 15.3 & 15.6 & \\
\hline Monnazzi et al. (2012) [17] & & Total & & & 16.5 & & & 14.6 & & & 27.1 & & & 16.4 \\
\hline \multirow{2}{*}{$\begin{array}{l}\text { Sekerci and Sisman } \\
\text { (2014) [20] }\end{array}$} & Turkish & Male & 18.2 & 17.3 & 16.8 & 13.6 & 14.0 & 13.0 & 35.5 & 36.3 & 33.4 & 17.2 & 15.9 & 15.3 \\
\hline & & Female & 16.0 & 15.6 & & 12.4 & 12.0 & & 30.9 & 30.9 & & 14.0 & 14.2 & \\
\hline Senel et al. (2015) [21] & & Total & 18.4 & 18.7 & 18.5 & 16.7 & 17.1 & 16.9 & 37.6 & 39.1 & 38.3 & 18.1 & 18.1 & 18.1 \\
\hline Lima et al. (2016) [15] & & Total & 18.7 & 20.0 & & 15.8 & 15.8 & & 33.5 & 33.9 & & 16.6 & 16.3 & \\
\hline \multirow[t]{2}{*}{ Zhou et al. (2017) [25] } & & Male & & & & & & 18.2 & & & 35.3 & & & 15.7 \\
\hline & & Female & & & & & & 17.0 & & & 30.5 & & & 15.5 \\
\hline Aps et al. (2018) [3] & & Total & 18.0 & 18.1 & & 14.9 & 15.0 & & 27.2 & 27.4 & & 15.9 & 15.5 & \\
\hline
\end{tabular}

ML-AM — mean distance between the mandibular lingula and the anterior border of the mandible; ML-PM — mean distance between the mandibular lingula and the posterior border of the mandible; $\mathrm{ML}-\mathrm{IM}$ - mean distance between the mandibular lingula and the inferior border of the mandible; $\mathrm{ML}-\mathrm{ML}$ - mean distance between the mandibular lingula and the mandibular notch; CBCT — cone-beam computed tomography

An elaborate description of the morphology of the triangular type has been illustrated by Tuli et al. [23]. The tip of the lingula in the triangular type was directed towards the mandibular condyle in $89.4 \%$ of cases and towards the posterior border of the ramus in $10.6 \%$ of cases. Then, they described that the anterior or upper border of the lingula in the triangular type was attached to the mandibular ramus in $88.5 \%$ of cases and well separated from the mandibular ramus in $11.5 \%$ of cases. They also depicted more details of the truncated type. The lingula in the truncated type had 3 borders - superior, inferior, and posteriorand between them were superior and inferior angles, directed towards the mandibular condyle and the posterior border of ramus, respectively. The posterior border of the lingula was slightly convex upwards in $69.2 \%$, straight in $19.2 \%$, and concave in $11.5 \%$ of cases.

\section{LOCATION OF THE MANDIBULAR LINGULA}

The position of the lingula has been described using several reference points or lines, such as the anterior and posterior border of the mandibular ramus, the deepest point of the mandibular notch, inferior border of the mandible, and the plane parallel to the occlusal plane (Table 1). The location of the lingula is affected by various factors, such as gender, age, and ethnicity. Even so, the mandibular lingula maintained the ratio location in a more posterior and superior position related to the central point of the mandibular ramus $[15,17,19,21,24]$. This was valid in all analysed gender and age groups, despite the entire mandibular growth [3], and whether the mandible was dentulous or edentulous [13]. It is also commonly proposed that the measurements in females were shorter than those observed in males [8, 20, 25].

The location of the lingula varies significantly with the skeletal pattern. Prognathic mandibles have a lingula that is located more posterior and superior than non-prognathic mandibles [2, 22]. Jung et al. [9] evaluated the location of the lingula in skeletal class I and class III patients using panoramic radiographs and concluded that most of the lingulae coincide with the level of the coronoid notch in skeletal class I patients and higher than the coronoid notch in class III patients.

Most of the lingulae are located above the occlusal plane, but it is occasionally located at or below the occlusal plane. According to Jansisyanont et al. [8], it was found that $80.1 \%$ of lingulae were above the occlusal plane and $19.9 \%$ of them were below the occlusal plane. Zhou et al. [25] found that only $0.8 \%$ of the lingulae were below the occlusal plane and $0.8 \%$ of them levelled with the occlusal plane. Aps et al. [3] studied the location of the mandibular lingula using CBCT data of paediatric patients who were 6 to 18 years old. All subjects were categorised according to age (6-9, 10-13, and 14-18 years old), and the lingulae were compared with the occlusal plane. In 
total, $8.9 \%$ of the lingulae were located at or below the occlusal plane. As age increased, this anatomical feature showed a tendency to decrease. The number of lingulae below the occlusal plane is more numerous in the youngest group, while it is relatively unusual in adolescents between the ages of 14 and 18 years (Table 2).

A relationship has been discovered between the location of the lingula and its shape in the mandibular ramus. The lingula of the triangular shape was generally located slightly more superior and posterior than other shapes. It is important to consider this trend when performing surgical procedures including the mandibular ramus [9].

\section{CLINICAL CONSIDERATIONS RELATED TO INFERIOR ALVEOLAR NERVE BLOCK}

As there is a great degree of variability regarding the position of the mandibular lingula; it is difficult to define the accurate needling position and depth during the inferior alveolar nerve block. If the position of the lingula in the mandibular ramus can be confirmed, it will be much easier to achieve successful anaesthesia of the inferior alveolar nerve.

The location of the lingula was investigated, and the ideal injection point for inferior alveolar nerve block was suggested in previous studies. The horizontal distance from the anterior border of the mandibular ramus to the mandibular lingula (or mandibular foramen) was measured. The mean values are recommended as injection sites to deliver anaesthesia as safely and as effectively as possible (Table 3 ) $[3,7,8,20]$.

The recommended injection point varied among the different authors. Some reasons may explain why there are different values for each study. All subjects used in the studies had individual variations in anatomy. Some of the mandibles had a very pointed tip of the lingula, leading to a large length, while others had distinctly different lingula shapes on either side. Such anatomical variations may confuse the resulting distance and explain why there are different values for each study. Second, for the lingula to be fully visualised, the opacity and brightness of the $C B C T$ images were adjusted. The manipulation of the image may have caused variability in some measurements. Another reason relates to the ethnic and racial backgrounds of the patients.

The proposed vertical location of the ideal injection site for the inferior alveolar nerve was based on the occlusal plane as a reference plane. Jansisyanont
Table 2. Percentage of the lingula at or below the occlusal plane

\begin{tabular}{lccc}
\hline $\begin{array}{l}\text { Author (year) } \\
\text { [Reference] }\end{array}$ & $\begin{array}{c}\text { Ages } \\
\text { [years] }\end{array}$ & Study design & $\begin{array}{c}\text { At or below the } \\
\text { occlusal plane (\%) }\end{array}$ \\
\hline $\begin{array}{l}\text { Jansisyanont et al. } \\
\text { (2009) [8] }\end{array}$ & $18-83$ & $\begin{array}{c}\text { Dry } \\
\text { mandible }\end{array}$ & $19.9 \%$ \\
Zhou et al. (2017) [25] & $18-36$ & CBCT & $1.6 \%$ \\
Aps et al. (2018) [3] & $6-18$ & CBCT & $8.9 \%$ \\
& $6-9$ & & $6.1 \%$ \\
& $10-13$ & & $2.5 \%$ \\
& $14-18$ & & $0.4 \%$ \\
\hline
\end{tabular}

CBCT — cone-beam computed tomography

Table 3. Mean values of horizontal location of the lingula or the mandibular foramen and the ideal injection point from anterior mandible (AM) for inferior alveolar nerve block suggested in previous studies

\begin{tabular}{|c|c|c|c|c|}
\hline \multirow[t]{2}{*}{$\begin{array}{l}\text { Author (year) } \\
\text { [Reference] }\end{array}$} & \multirow[t]{2}{*}{ Study design } & \multicolumn{2}{|c|}{$\begin{array}{l}\text { Mean distance } \\
{[\mathrm{mm}]}\end{array}$} & \multirow{2}{*}{$\begin{array}{c}\text { Suggested } \\
\text { injection } \\
\text { point from } \\
\text { AM }\end{array}$} \\
\hline & & ML-AM & MF-AM & \\
\hline $\begin{array}{l}\text { Jansisyanont et } \\
\text { al. (2009) [8] }\end{array}$ & Dry mandible & 20.6 & & 20.6 \\
\hline $\begin{array}{l}\text { Sekerci et al. } \\
\text { (2014) [20] }\end{array}$ & СВCT & 16.77 & & 16.7 \\
\hline $\begin{array}{l}\text { Findik et al. } \\
\text { (2014) [7] }\end{array}$ & СВCT & & $\begin{array}{l}\text { R: } 15.27 \\
\text { L: } 15.41\end{array}$ & 15 \\
\hline $\begin{array}{l}\text { Aps et al. } \\
\text { (2018) [3] }\end{array}$ & СВCT & $\begin{array}{l}\text { R: } 18.0 \\
\text { L: } 18.12\end{array}$ & & 18 \\
\hline
\end{tabular}

$\mathrm{ML}-\mathrm{AM}$ - mean distance between the mandibular lingula and the anterior border of mandible; MF-AM - mean distance between the mandibular foramen and the anterior border of the mandible; AM — anterior border of mandible; CBCT — cone-beam computed tomography; $\mathrm{L}$ - left; $\mathrm{R}$ - right

et al. [8] and Sekerci et al. [20] measured the distance between the lingula and occlusal plane. The mean values were recommended as an injection site. Aps et al. [3] recommended a larger distance from the occlusal plane than other studies. They classified patients into three groups according to age and estimated the location of the lingula related to the occlusal plane. As age increased, the mean value of the distance from the occlusal plane to the lingula increased. The maximum distance also increased with age. They suggested that clinicians should theoretically aim at the maximum value (14 $\mathrm{mm}$ above all age groups) from the occlusal plane for mandibular block anaesthesia. Aiming for the maximum value from the occlusal plane as opposed to the mean value would prevent the clinician from injecting the needle too low and causing failure of the nerve block (Table 4). 
Table 4. Mean values of vertical location of the lingula and the ideal injection point from the occlusal plane for inferior alveolar nerve block suggested in previous studies

\begin{tabular}{lccccc}
\hline Author (year) [Reference] & Study design & \multicolumn{3}{c}{ ML-OC [mm] } & Suggested injection point \\
\cline { 3 - 5 } & & Mean & Minimum & Maximum & 4.5 \\
\hline Jansisyanont et al. (2009) [8] & Dry mandible & 4.5 & 0.6 & 13.1 & 3.6 \\
Sekerci et al. (2014) [20] & CBCT & 3.6 & 1.3 & 8.2 & 14 \\
Aps et al. (2018) [3] & CBCT & R: 5.11 & R: -2.77 & R: 13.29 & \\
& & L: 4.43 & L: -5.93 & L: 13.65 & \\
\hline
\end{tabular}

$\mathrm{ML}-\mathrm{OC}$ — distance between the mandibular lingula and the occlusal plane; $\mathrm{CBCT}$ — cone-beam computed tomography; $\mathrm{L}$ - left; $\mathrm{R}$ — right

The mandibular lingula is an important anatomical landmark, and accurate information for exact lingula features is required during inferior alveolar nerve block anaesthesia. Proper evaluation of the lingula is key to effective anaesthesia and decreases the failure rate of the inferior alveolar nerve in clinical practices of the mandible.

\section{Funding}

This work was supported by the National Research Foundation of Korea (NRF) grant funded by the Korea government (MSIT) (No. 2020R1C1C1003237).

\section{Conflict of interest: None declared}

\section{REFERENCES}

1. Ahn BS, Oh SH, Heo CK, et al. Cone-beam computed tomography of mandibular foramen and lingula for mandibular anesthesia. Imaging Sci Dent. 2020; 50(2): 125-132, doi: 10.5624/isd.2020.50.2.125, indexed in Pubmed: 32601587

2. Akcay H, Kalabalık F, Tatar B, et al. Location of the mandibular lingula: Comparison of skeletal Class I and Class III patients in relation to ramus osteotomy using cone-beam computed tomography. J Stomatol Oral Maxillofac Surg. 2019; 120(6): 504-508, doi: 10.1016/j. jormas.2019.07.013, indexed in Pubmed: 31404678.

3. Aps JKM, Gazdeck LY, Nelson T, et al. Assessment of the location of the mandibular lingula in pediatric patients using cone beam computed tomography images. . J Dent Child (Chic). 2018; 85(2): 58-65, indexed in Pubmed: 30345955.

4. Asdullah M, Ansari AA, Khan MH, et al. Morphological variations of lingula and prevalence of accessory mandibular foramina in mandibles: A study. Natl J Maxillofac Surg. 2018; 9(2): 129-133, doi: 10.4103/njms.NJMS_13_16, indexed in Pubmed: 30546225.

5. Desai VC, Desai S, Shaik HS. Morphological study of mandible. J Pharmaceut Sci Res. 2014; 6(4): 175.

6. Fabian FM. Observation of the position of the lingula in relation to the mandibular foramen and the mylohyoid groove. Ital J Anat Embryol. 2006; 111(3): 151-158, indexed in Pubmed: 17312921.

7. Findik Y, Yildirim D, Baykul T. Three-dimensional anatomic analysis of the lingula and mandibular foramen: a cone beam computed tomography study. J Craniofac
Surg. 2014; 25(2): 607-610, doi: 10.1097/SCS.0b013e3182a30ec3, indexed in Pubmed: 24448541.

8. Jansisyanont $\mathrm{P}$, Apinhasmit W, Chompoopong S. Shape, height, and location of the lingula for sagittal ramus osteotomy in Thais. Clin Anat. 2009; 22(7): 787-793, doi: 10.1002/ca.20849, indexed in Pubmed: 19644966.

9. Jung $\mathrm{YH}, \mathrm{Cho} \mathrm{BH}$, Hwang JJ. Location and shape of the mandibular lingula: Comparison of skeletal class I and class III patients using panoramic radiography and cone-beam computed tomography. Imaging Sci Dent. 2018; 48(3): 185-190, doi: 10.5624/isd.2018.48.3.185, indexed in Pubmed: 30276155.

10. Kanno CM, de Ol, Cannon M, et al. The mandibular lingula's position in children as a reference to inferior alveolar nerve block. J Dent Child (Chic). 2005; 72(2): 56-60, indexed in Pubmed: 16294933.

11. Keros J, Kobler P, Baucić I, et al. Foramen mandibulae as an indicator of successful conduction anesthesia. Coll Antropol. 2001; 25(1): 327-331, indexed in Pubmed: 11787558.

12. Khoury JN, Mihailidis S, Ghabriel M, et al. Applied anatomy of the pterygomandibular space: improving the success of inferior alveolar nerve blocks. Aust Dent J. 2011; 56(2): 112-121, doi: 10.1111/j.1834-7819.2011.01312.x, indexed in Pubmed: 21623801.

13. Kim HJ, Lee HY, Chung IH, et al. Mandibular anatomy related to sagittal split ramus osteotomy in Koreans. Yonsei Med J. 1997; 38(1): 19-25, doi: 10.3349/ ymj.1997.38.1.19, indexed in Pubmed: 9100479.

14. Kositbowornchai S, Siritapetawee M, Damrongrungruang T, et al. Shape of the lingula and its localization by panoramic radiograph versus dry mandibular measurement. Surg Radiol Anat. 2007; 29(8): 689-694, doi: 10.1007/s00276007-0270-9, indexed in Pubmed: 17960323.

15. Lima FJC, Oliveira Neto OB, Barbosa FT, et al. Location, shape and anatomic relations of the mandibular foramen and the mandibular lingula: a contribution to surgical procedures in the ramus of the mandible. Oral Maxillofac Surg. 2016; 20(2): 177-182, doi: 10.1007/s10006-0160547-4, indexed in Pubmed: 26781719.

16. Lopes P, Pereira G, Santos A. Morphological analysis of the lingula in dry mandibles of individuals in Southern Brazil. J Morphol Sci. 2017; 27(3-4).

17. Monnazzi MS, Passeri LA, Gabrielli MFR, et al. Anatomic study of the mandibular foramen, lingula and antilingula in dry mandibles, and its statistical relationship between the true lingula and the antilingula. Int J Oral Maxillofac Surg. 2012; 41(1): 74-78, doi: 10.1016/j. ijom.2011.08.009, indexed in Pubmed: 21955366. 
18. Nusstein J, Reader Al, Beck FM. Anesthetic efficacy of different volumes of lidocaine with epinephrine for inferior alveolar nerve blocks. Gen Dent. 2002; 50(4): 372-5; quiz 376, indexed in Pubmed: 12640855.

19. Samanta $P$, Kharb P. Morphological analysis of the lingula in dry adult human mandibles of north Indian population. J Cranio-Maxillary Diseases. 2012; 1(1): 7, doi: 10.4103/2278-9588.102467.

20. Sekerci $A E$, Sisman $Y$. Cone-beam computed tomography analysis of the shape, height, and location of the mandibular lingula. Surg Radiol Anat. 2014; 36(2): 155-162, doi: 10.1007/ s00276-013-1150-0, indexed in Pubmed: 23793815.

21. Senel B, Ozkan A, Altug HA. Morphological evaluation of the mandibular lingula using cone-beam computed tomography. Folia Morphol. 2015; 74(4): 497-502, doi: 10.5603/FM.2015.0114, indexed in Pubmed: 26620512 .
22. Tengku Shaeran TA, Shaari R, Abdul Rahman S, et al. Morphometric analysis of prognathic and non-prognathic mandibles in relation to BSSO sites using CBCT. J Oral Biol Craniofac Res. 2017; 7(1): 7-12, doi: 10.1016/j.jobcr.2016.10.007, indexed in Pubmed: 28316914.

23. Tuli A, Choudhry R, Choudhry S, et al. Variation in shape of the lingula in the adult human mandible. J Anat. 2000; 197 ( Pt 2): 313-317, doi: 10.1046/j.14697580.2000.19720313.x, indexed in Pubmed: 11005723.

24. Woo SS, Cho JY, Park WH, et al.. A study of mandibular anatomy for orthognathic surgery in Koreans. J Korean Ass Oral Maxillofacial Surgeons. 2002; 28(2): 126-131.

25. Zhou C, Jeon $\mathrm{TH}$, Jun $\mathrm{SH}$, et al. Evaluation of mandibular lingula and foramen location using 3-dimensional mandible models reconstructed by cone-beam computed tomography. Maxillofac Plast Reconstr Surg. 2017; 39(1): 30, doi: 10.1186/ s40902-017-0128-y, indexed in Pubmed: 29109943. 